\title{
Perspectivas adotadas pelos cuidadores na interação com a criança institucionalizada
}

Perspectives adopted by caregivers in the interaction with the institutionalized child

Perspectivas adoptadas por los cuidadores en la interacción con el niño institucionalizado

\section{Ruth Irmgard Bärtschi Gabatz ${ }^{\text {I }}$ Eda Schwartz ${ }^{\text {II }}$, Viviane Marten Milbrath ${ }^{\text {III }}$}

\begin{abstract}
Resumo: Objetivo: compreender as perspectivas do cuidador a partir de sua interação com as crianças institucionalizadas. Método: pesquisa qualitativa que utilizou a Teoria Fundamentada nos Dados e o Interacionismo Simbólico para elaboração e análise dos dados. Os dados foram coletados de abril a julho de 2015, por meio de uma entrevista intensiva, com 15 cuidadoras em uma instituição de acolhimento infantil. Resultados: são apresentados em três categorias: Aprendendo a valorizar sua vida e sua família; Mudando a forma de ver e lidar com os outros; Percebendo a criança como ser capaz de mudar sua realidade. Considerações finais: identificou-se que na interação com a criança institucionalizada, a cuidadora passa a adotar novas formas de ver e agir no mundo, valorizando mais sua vida e sua família, além de desenvolver mais paciência, compaixão e amor por outras pessoas em condições de vulnerabilidade.
\end{abstract}

Descritores: Relações interpessoais; Cuidadores; Criança institucionalizada; Enfermagem

\begin{abstract}
Aim: to understand the perspectives of the caregiver based on their interaction withthe institutionalized children. Method: qualitative research using Grounded Theory and Symbolic Interactionism for data elaboration and analysis. The data were collected from April to July 2015, through an intensive interview, with 15 caregivers in a child care institution. Results: are presented in three categories: Learning to value life and family; Changing the way you see and deal with others; Understanding the child as a personable to change their reality. Final considerations: it was identified that in the interaction with the institutionalized child, the caregiver starts adopting new ways of seeing and acting in the world, valuing his/her life and family, besides developing more patience, compassion and love for other people in conditions of vulnerability.
\end{abstract}

Descriptors: Interpersonal relations; Caregivers; Child, institutionalized; Nursing

IEnfermeira, Doutora em Ciências, Professora Adjunta da Faculdade de Enfermagem da Universidade Federal de Pelotas, Pelotas, Rio Grande do Sul, Brasil. e-mail: r.gabatz@yahoo.com.br

IIEnfermeira, Pós- Doutora em Enfermagem, Professora Associada da Faculdade de Enfermagem e Programa de Pós-graduação em Enfermagem da Universidade Federal de Pelotas, Pelotas, Rio Grande do Sul, Brasil. E-mail: eschwartz@terra.com.br

IIIEnfermeira, Doutora em Enfermagem, Professora Adjunta da Faculdade de Enfermagem e do Programa de Pós-graduação em Enfermagem da Universidade Federal de Pelotas, Pelotas, Rio Grande do Sul, Brasil. E-mail: vivianemarten@hotmail.com 
Resumen: Objetivo: comprender las perspectivas del cuidador a partir de su interacción con los niños institucionalizados. Método: investigación cualitativa basada enla Teoría Fundamentada en los Datos y el Interaccionismo Simbólico para elaboración y análisis de los datos. Los datos fueron recolectados de abril a julio de 2015, por medio de una entrevista intensiva, con 15 cuidadoras, en una institución de acogida infantil. Resultados: se presentaron tres categorías: aprendiendo a valorar su vida y su familia; cambiando la forma de ver y tratarcon los demás; comprendiendo elniño como ser capaz de cambiar su realidad. Consideraciones finales: se identificóque en la interacción con el niño institucionalizado, la cuidadora pasa a adoptar nuevas formas de ver y actuar en el mundo, valorando más su vida y su familia, además de desarrollar más paciencia, compasión y amor por otras personas en condiciones de vulnerabilidad.

Descriptores: Relaciones interpersonales; Cuidadores; Niño institucionalizado; Enfermería

\section{Introdução}

A socialização cumpre um papel fundamental no desenvolvimento do ser humano, sendo que convivência com outras pessoas guia esse ser a aprender a lidar com as situações apresentadas na sua vida. ${ }^{1}$ Em geral, a socialização primária ocorre na família, contudo, quando a criança é privada da convivência familiar, por se encontrar em situação de risco pessoal e social, ela pode ser encaminhada a uma instituição de acolhimento. As instituições de acolhimento possuem, historicamente, a função de cuidar e manter crianças e adolescentes que não podem permanecer com suas famílias. ${ }^{2}$

$\mathrm{Na}$ institucionalização, ocorre uma fragilização dos laços da criança com sua família e sua comunidade de origem, sendo necessária a adaptação a uma nova realidade com pessoas desconhecidas. Nesse sentido, é importante que os cuidadores estejam instrumentalizados para receber e assistir as crianças, propiciando cuidados e educação recursos de enfrentamento às dificuldades e desenvolvimento afetivo, cognitivo e social dos acolhidos. ${ }^{3}$

Nesse contexto, inserem-se o referencial teórico do Interacionismo Simbólico, a partir de três premissas: a primeira é que o ser humano age em relação às coisas tomando como base os significados que estas têm para ele. ${ }^{4}$ Assim, cuidadores e crianças convivem e interagem dentro das instituições de acolhimento, podendo construir significados diversos sobre os objetos, uma vez que são influenciados por pessoas com concepções distintas, provindas de culturas e realidades diferentes entre si. A segunda premissa é que o significado das coisas surge pela 
interação social que um ser tem com seus companheiros. ${ }^{4}$ Nesse sentido, na interação com a criança institucionalizada e com seus pares, os cuidadores são influenciados nos sentidos e significados que atribuem às coisas. A terceira premissa é que os significados são manuseados e modificados por meio de um processo interpretativo usado pela pessoa para lidar com as coisas com que se defronta, sendo o significado das coisas formado, aprendido e transmitido por meio de um processo social. ${ }^{4}$ Desse modo, no processo de formação de vínculo com a criança, o cuidador, por meio da interação, passa a criar e recriar sua perspectiva acerca do mundo ao seu redor.

Então, na interação com a criança institucionalizada e com seus pares, o cuidador, ao conviver com pessoas diferentes, provindas de realidades e culturas diversas, cria e recria suas perspectivas, sendo estas permeadas pelas subjetividades dos indivíduos com os quais interage, construindo uma realidade multifacetada e modificando suas perspectivas. Ao mesmo tempo, a criança passa a seguir os modelos de cuidado apresentados pelos cuidadores. Portanto, os cuidadores servem de modelos identificatórios, protegendo e orientando as crianças, representando um papel central em suas vidas. ${ }^{5}$ Nesse sentido, torna-se importante explorar mais acerca da temática, buscando conhecer as perspectivas desses cuidadores na interação com a criança institucionalizada.

Com base nesses pressupostos, elaborou-se a questão norteadora: Que perspectivas o cuidador adota a partir de sua interação com a criança institucionalizada? Objetivando-se compreender as perspectivas do cuidador a partir de sua interação com as crianças institucionalizadas.

\section{Método}

Trata-se de um estudo com abordagem qualitativa, em que se utilizou a Teoria Fundamentada nos Dados (TFD) ou Grounded Theory como referencial metodológico ${ }^{6}$ e o 
Perspectivas adotadas pelos cuidadores na interação com a criança institucionalizada | 4

Interacionismo Simbólico como referencial teórico. ${ }^{4}$ Este estudo apresenta uma análise aprofundada da subcategoria "Aprendendo com a criança", que faz parte do processo de construção do modelo teórico "Percebendo o trabalho/cuidado com crianças institucionalizadas", elaborado na tese de doutorado "Formação de vínculos e interação entre cuidadores e crianças em um abrigo".

O cenário da pesquisa foi um abrigo institucional que recebe crianças do sexo masculino e feminino, de zero a oito anos de idade, localizado em um município do sul do estado do Rio Grande do Sul. As crianças acolhidas nessa instituição são encaminhadas pelo Juizado de Menores e pelo Conselho Tutelar, pois não podem permanecer com as suas famílias.

Os participantes da pesquisa foram os profissionais envolvidos nos cuidados diretos às crianças de zero a três anos de idade nos turnos da manhã, tarde e noite, totalizando 15 pessoas. Consideram-se como cuidados diretos todas as atividades realizadas pelos cuidadores com as crianças que propiciam o contato físico e visual constante: alimentação, banho, troca de fraldas, auxílio para engatinhar e caminhar, atividades lúdicas e de aprendizagem, aconchegar ao colo, embalar, entre outras. $\mathrm{Na}$ instituição em questão, haviam 24 cuidadoras, sendo que 16 delas atuavam no cuidado das crianças de zero a três anos de idade.

Os critérios de inclusão no estudo foram: trabalhar na instituição há, pelo menos, três meses e prestar cuidados diretos às crianças de zero a três anos de idade acolhidas na instituição. Todas as cuidadoras que atendiam aos critérios de inclusão aceitaram participar do estudo.

Os dados foram coletados no período de abril a julho de 2015, nos três turnos (manhã, tarde e noite), agendando-se as visitas previamente, de acordo com a disponibilidade das cuidadoras e do abrigo. Para tanto, utilizou-se a entrevista intensiva com as cuidadoras, contendo questões norteadoras amplas e abertas, ${ }^{6}$ entrevistando-se 15 cuidadoras. A entrevista intensiva possibilita uma análise detalhada de determinado tema, proporcionando a explicação da interpretação de cada participante sobre sua experiência. ${ }^{6}$ As entrevistas tiveram duração média de 30 minutos, 
gravadas em aparelho MP3 e transcritas manualmente na íntegra, foram realizadas em uma sala privativa dentro da instituição de acolhimento.

Na Teoria Fundamentada Construtivista defendida por Kathy Charmaz, ocorre uma coconstrução e reconstrução de dados em direção à teoria. ${ }^{7}$ Para tanto, os dados são analisados por meio de uma codificação inicial e, posteriormente, codificação focalizada, sendo que a teoria surge com a interpretação reflexiva do pesquisador sobre o contexto investigado.

Assim, os dados foram gravados, transcritos e analisados juntamente com a coleta, sendo que, a cada nova entrevista ou observação, avaliaram-se as informações codificando-as e categorizando-as voltando, posteriormente, ao campo para continuar e complementar a coleta.

Foram observados os preceitos éticos de acordo com o proposto pela Resolução no 466 de dezembro de $2012 .{ }^{8}$ Para tanto, foi solicitada uma carta de anuência elaborada pela instituição coparticipante e disponibilizado um Termo de Consentimento Livre e Esclarecido aos cuidadores que concordaram em participar. O anonimato dos participantes da pesquisa foi mantido, de forma que se utilizou para as cuidadoras a letra $C$ seguida de um numeral sequencial $(C 1, C 2, \ldots)$. Antes da realização do estudo, ele foi aprovado pelo Comitê de Ética da Faculdade de Enfermagem da Universidade Federal de Pelotas, no dia 26 de abril de 2015, sob o Certificado de Apresentação para Apreciação Ética (CAAE) 42696915.9.0000.5316, parecer número 1035995.

\section{Resultados e discussões}

Participaram do estudo 15 cuidadoras com idades entre 22 e 58 anos, grau de instrução do ensino fundamental completo ao ensino superior completo e tempo de atuação na instituição de oito meses a 12 anos. Nove eram solteiras, quatro casadas, uma divorciada e uma vivia em concubinato. Além disso, nove possuíam filhos.

O cuidado à criança institucionalizada traz diversos aprendizados para as cuidadoras, elas passam a ver a vida sob outra perspectiva, valorizando mais a sua própria família, as suas 
conquistas, além de se sensibilizarem mais com a condição do outro, em especial, das crianças abandonadas. Dessa forma, foi possível elaborar três categorias: Aprendendo a valorizar sua vida e sua família; Mudando a forma de ver e lidar com os outros; Percebendo a criança como ser capaz de mudar sua realidade.

\section{Aprendendo a valorizar sua vida e sua família}

O cuidado da criança institucionalizada faz as cuidadoras refletirem sobre sua própria vida e condição, sendo que passam a valorizar muito mais o que possuem e serem felizes por isso.

Eu aprendi que eu sou feliz e eu tenho tudo [...]. Depois que eu pisei o pé no abrigo que eu comecei a repensar a minha vida. Comecei a dar valor para tudo, até para minha humilde casa [...]. Mais o valor familiar, o vínculo familiar, [...]. (C1)

[...] eu acho que, primeiramente com eles, tu aprende a dar valor àquilo que tu tens, [...] essas crianças daqui não têm o mínimo que é uma família, [...] mesmo assim estão ali, estão rindo, estão brincando, aquela inocência, então, assim tu aprende a dar valor àquilo que tu tens. (C11)

$\mathrm{Na}$ interação com a criança institucionalizada, as cuidadoras ressignificam suas próprias vidas e passam a ver suas conquistas e famílias positivamente. A família e o vínculo com ela são mais valorizados pelas cuidadoras, pois percebem que possuem algo que as crianças não têm, mas, mesmo assim, estão rindo e brincando. Os significados são manuseados e modificados por meio do processo interpretativo usado pela pessoa para lidar com as coisas com que se defronta. ${ }^{4}$ Assim, não só as crianças criam e recriam suas perspectivas no convívio com as cuidadoras, mas também as cuidadoras modificam sua percepção sobre a vida na interação social que têm com as crianças institucionalizadas.

Situações extremas tal como a institucionalização infantil podem mudar a vida das pessoas. Em busca de superação, ocorre a mudança nos hábitos, levando ao amadurecimento e crescimento pessoal, bem como ao fortalecimento dos laços familiares. ${ }^{9}$ 
As cuidadoras, ao experienciar uma realidade diferente da sua, passam a repensar sua própria vida e a forma como lidam com ela, dando menos valor às pequenas dificuldades e agradecendo pelo que possuem.

É bom que tu conheças uma realidade diferente do que tu vives e tu aprendes também a lidar com isso dentro de ti, com aquela parte [...] de reclamar da vida. [...] tu vens para cá e tu vê as crianças também piores que tu, e tu tens que olhar para ti e agradecer por ter uma casa, por ter uma familia. (C12)

Estudo aponta que quando os profissionais vivenciam situações extremas no cuidado da criança, passam a valorizar mais a vida, mudando seus valores e princípios e se tornando seres mais humanos. ${ }^{10}$ Desse modo, é possível compreender o poder da experiência para o ser humano, pois é a partir dela que constrói e modifica suas perspectivas diante das coisas da vida. A vivência de situações difíceis faz com que os indivíduos passem a reconhecer sua condição de vida de forma mais positiva, valorizando o que possuem e diminuindo a importância das coisas frívolas.

\section{Mudando a forma de ver e lidar com os outros}

$\mathrm{Na}$ interação durante o cuidado da criança, as participantes referem que passaram a ter mais amor, compreensão, solidariedade, paciência e empatia com os outros.

[...] eu cultivei mais um amor, não que eu não tivesse amor, mas aquilo me despertou mais. Hoje eu vejo crianças na rua com a mãe catando alimento, aquilo dói na gente assim sabe. Então, isso eu acho que aflorou, me sensibilizou mais. (C3)

Destaca-se na fala de C3 o cultivo do amor como um sentimento que foi despertado na relação com a criança institucionalizada e em outras situações de vulnerabilidade vivenciadas por crianças. Outro estudo com cuidadoras de crianças com incapacidade mostrou o amor como valor principal, sendo ele o primeiro motor do comportamento humano. ${ }^{11}$ 
Perspectivas adotadas pelos cuidadores na interação com a criança institucionalizada I 8

Complementarmente ao amor, aflora também a compaixão pelo outro, que faz com que a cuidadora se torne "mais humana", passando a entender que nem sempre é possível que as dificuldades se resolvam imediatamente e que é necessário considerar a perspectiva dos outros de forma mais paciente.

[...] a ser mais humana, mais compreensível, mais tolerante. Nós temos os nossos ganhos [...]. (C6)

[...] a gente aprende a valorizar as coisas, que a gente é muito, eu também sou, quero que tudo se resolva logo. Então, tu entende que não é assim, que tem que esperar, tem que ter muita paciência com as colegas [...]. (C8)

Diante das dificuldades experienciadas pelas crianças institucionalizadas, as cuidadoras adotam uma nova postura diante da sua própria existência, sendo mais compreensíveis e tolerantes. Estudo realizado com pais de crianças e adolescentes com câncer mostrou que o ser humano transcende a sua própria dor e passa "a viver autenticamente no mundo, tornando-se um Ser de preocupação consigo e com o outro" ${ }^{12: 560}$ Complementarmente, a paciência é um elemento essencial no cuidar, sendo que aprender a ter paciência e tolerância ajuda o indivíduo a lidar com frustrações e conflitos. ${ }^{13}$ As cuidadoras apontam ainda, nos relatos acima, que essa nova postura adotada por elas é um ganho obtido na interação com a criança institucionalizada.

O cuidado da criança traz diferentes aprendizados, C10 destaca que, além de aprender a lidar com paciência, aprendeu também a valorizar coisas para as quais antes não dava tanta importância, como por exemplo, a deambulação. Para uma criança sadia, essa pode ser normal, enquanto que para outra com problemas é uma grande conquista:

[...] tu aprendes a lidar com a tua paciência. [...] tu aprendes a dar valor a coisas que tu talvez não percebesses, passa a perceber [...]. Porque antes [...] a criança começou a caminhar, 'ah normal', logo o meu filho que [...] tem condições [...], mas [...] de repente uma criança, que não tem talvez essa condição assim, aí ela começou a caminhar, porque médicos disseram que ela não podia, hoje ela pode, para nós é muito bom. (C10) 
As cuidadoras de crianças com incapacidades severas sentem-se recompensadas quando percebem um avanço físico nas crianças ou a manifestação afetiva por sua parte. ${ }^{11}$ Assim, uma condição considerada "normal” dentro do desenvolvimento físico e, por isso, pouco valorizada, passa a representar algo muito valioso quando ocorre em circunstâncias adversas. Isso estimula a percepção acerca dos pequenos avanços apresentados pelas crianças com maior vulnerabilidade.

As participantes referem que aprenderam a se doar e criar vínculos afetivos e carinho por crianças que nem são suas familiares, trocando com essas crianças afeto e amor:

[...] aprendes a te doar mais, [...] tu aprendes a dar amor e tu crias vínculo afetivo, tu crias amor, por uma criança, por um ser humano que não é nada teu, que não tem teu sangue, que não tem teu parentesco, mas tu crias aquele carinho, e a criança a mesma coisa. [...] a gente aprende a trocar, não só dar, mas receber também, porque a criança te dá carinho, te dá amor, e é gratuito, o amor da criança é gratuito, é uma coisa assim sem interesse, sem nada. (C11)

O afeto é relevante para o desenvolvimento do ser humano, exercendo influência na sua socialização. Portanto, a partir do momento que a cuidadora oferece seu afeto à criança, cria uma relação afetiva, recebendo também o carinho da criança, desenvolvendo-se uma 'troca de cuidados'. Salienta-se que as relações afetivas desde idades precoces são indispensáveis para que ocorra interatividade do indivíduo com o meio, favorecendo a sua socialização. ${ }^{14}$ É por meio da interação com a criança que se torna possível a comunicação com ela. Nesse sentido, "afeto, amor e convivência fortalecem os vínculos e permitem reconhecer as manifestações da criança”. ${ }^{5: 50}$

Nesse contexto, a responsividade materna aos estímulos lançados pelo bebê indica sua percepção diante das intenções comunicativas dele. Respondendo sensivelmente a esses estímulos, a mãe poderá ser capaz de "adotar práticas de socialização facilitadoras do desenvolvimento socioemocional infantil no futuro". ${ }^{16: 312}$ Compreendendo-se que, na institucionalização infantil, a cuidadora representa a função materna, salienta-se que o vínculo 
afetivo na relação cuidadora/criança é indispensável para a elaboração e a manutenção de um ambiente saudável, atuando sobre o desenvolvimento da capacidade de vinculação. ${ }^{17}$

$\mathrm{Na}$ relação de troca entre cuidadora e crianças, o vínculo afetivo se fortalece, sendo que ambas obtêm ganhos. Nesse sentido, a forma com que a criança é capaz de se doar acaba por transformar o cotidiano da cuidadora:

[...] a gente aprende que a criança tem uma maneira pura de se doar. (C5)

No processo de interação, os indivíduos são ativos e aprendem a dar significado às coisas, valorizando o significado atribuído às suas experiências. ${ }^{4}$ Dessa forma, as cuidadoras, por meio da interação com as crianças, podem interagir agindo, percebendo, interpretando e agindo novamente, sendo atores e reatores no processo ativo no mundo ressignificando, assim, sua realidade.

Por meio da vivência da troca de sentimentos e carinho, a cuidadora aprende a mudar sua forma de agir perante as situações com as quais se depara no cotidiano, dentro e fora da instituição. Assim, procura ajudar mais os outros, respeitando os seres humanos:

Eu aprendi [...] a gente tem que [...] ajudar o próximo sempre que a gente puder. Ajudar o próximo, que tem muita gente que tem os pais e mães que os filhos estão aqui, porque não podem, não é porque não querem dar, é porque não têm condições. Então, se a gente puder, ajuda. (C13)

Fica evidente na fala de C13 que as condições que levam a criança ao acolhimento nem sempre estão relacionadas à falta de vontade dos pais e, sim, à impossibilidade de suprir suas necessidades. Assim, a cuidadora compreende que ajudando os outros pode auxiliar a diminuir os casos de acolhimento infantil decorrentes da incapacidade dos pais de atenderem às necessidades dos seus filhos. Desse modo, observando a situação da criança institucionalizada, as cuidadoras passam a adotar novas perspectivas também fora da instituição:

[...] aprendi na minha vida lá fora a respeitar mais, a ter mais respeito pela pessoa. [...] a pessoa está precisando de ajuda, não me chamava muito à 
atenção [...], e vendo eles assim, parando num abrigo, [...], assim tu fica mais comovida, teu coração já muda. Então, isso mudou em mim a minha forma de querer ajudar as pessoas [...]. (C15)

Então, a interação com a criança institucionalizada faz com que a cuidadora se torne uma pessoa melhor, como afirma C10:

\section{[...] esse é o lado positivo de tu te tornares uma pessoa melhor. (C10)}

Para C7, a experiência de cuidado da criança institucionalizada que passa por situações extremas de sofrimento e depois é adotada por uma família, ensina que sempre existe uma recompensa e que, mesmo com muitas dificuldades, pode-se ter um futuro melhor:

[...] eu aprendi muito [...] nunca está tudo perdido, [...] eles passam por tanto sofrimento, mas que no final...], tinha alguma coisa guardada, estava reservado um melhor para eles. Então, eu sempre penso assim, que sempre tem uma coisa melhor para a gente, [...]. Se tu olhar para eles, para o dia a dia da gente aqui, olha o que as crianças passam, [...], que a maioria deles foi tão bem recompensada por uma família, que deu amor, que abriu o leque deles terem uma vida de criança, e um futuro melhor [...]. (C7)

Com base nos depoimentos, pode-se perceber a força que as experiências das cuidadoras diante da institucionalização infantil têm para modificar sua forma de agir no mundo, sendo que essas experiências fortalecem e aumentam a expressão dos valores humanos. As cuidadoras amadurecem como pessoas, extraindo algo positivo das experiências dolorosas, imprimindo assim um novo significado à sua própria existência. ${ }^{12}$

Diante da vivência dolorosa, o cuidador passa a ressignificar seu modo de ser, buscando um sentido autêntico para sua vida. A partir daí, ocorre um "esforço de mudança comportamental em que o indivíduo assume novos padrões de visão”. ${ }^{18: 623}$ Complementarmente, as cuidadoras desenvolvem mais empatia com as outras pessoas que manifesta-se no respeito, no amor ao próximo, na doação e no auxílio ao outro. 


\section{Percebendo a criança como ser capaz de mudar sua realidade}

A criança institucionalizada passa por diversas dificuldades tais como a negligência e a violência, que podem alterar o seu cotidiano e leva e ao acolhimento. Neste contexto, as cuidadoras percebem que a realidade das crianças institucionalizadas é diferente daquela de outras crianças que vivem em lares com pais amorosos, cercadas de cuidados:

\section{[...] o que eu aprendi é que é uma outra realidade. (C2)}

Conforme C2, a realidade da criança institucionalizada é diferente daquela realidade já vivenciada pela cuidadora na interação com outras crianças, como as de sua família. Assim, é necessário adotar uma postura diferenciada com as crianças institucionalizadas, evitando que elas revivam situações de estresse, conforme afirma C9:

[...] a gente aprende assim que a gente tem que ter paciência, porque são crianças que já sofreram maus tratos. A gente não pode gritar na frente delas, a gente não pode ter reações assim que lembrem alguma coisa. (C9)

A instituição de acolhimento só pode ser considerada como local de proteção quando os cuidadores proporcionam apoio e interação emocional positiva, fomentando relações horizontais e afetivas. ${ }^{19}$ Desse modo, se compreende que, no cuidado da criança institucionalizada, a cuidadora deve evitar sua 'revitimização', demonstrando sua interação afetiva e preocupação com a criança. Assim, uma constância maior nos cuidados, com atenção individualizada e contato estável e receptivo, reduz o risco de desenvolvimento do apego inibido e do comportamento desorganizado nas crianças. ${ }^{20}$

Por outro lado, C4 compreende que a criança institucionalizada é igual à criança não institucionalizada, já que se trata de uma criança e que ambas possuem os mesmos medos e fraquezas:

Aprendi que criança é criança. A criança de abrigo ela não é diferente da criança que a gente tem em casa, ela é criança igual. Ela tem os mesmos medos, ela tem as mesmas fraquezas, ela tem os mesmos anseios [...]. (C4) 
Portanto, cuidar de crianças, tanto institucionalizadas quanto daquelas que vivem com suas famílias, é um trabalho que necessita de dedicação, no qual a prática é diferente da teoria:

[...] então são várias lições que a gente, lições que eu pego que não é muito na teoria assim, o negócio é mais desenvolver, tanto dar atenção, quanto carinho, como a paciência. A paciência eu acho que é fundamental[...]. (C9)

Dessa forma, no desenvolvimento do cuidado diário, crianças e cuidadoras aprendem umas com as outras, de forma que passam a adotar novas maneiras de ver e agir no mundo. A C14 demonstra sua emoção ao relatar que as crianças aprendem com as cuidadoras, reproduzindo o que aprenderam com seus pares:

[...] eu acho que todos os dias a gente aprende uma coisa. [...] o que mais me emociona [...] é que às vezes a gente está em poucas trabalhando.Às vezes, é aquele horário de tumulto [...], aí tu vê o maiorzinho cuidado do menor. [...] um cuidar do outro, mesmo sendo uns pinguinhos de gente [...] a gente vê assim que o trabalho da gente vale a pena, porque eles aprenderam a dar carinho. (C14)

O desenvolvimento emocional na infância implica em mudanças contínuas na capacidade da criança de relacionar-se com o meio, assim como na maneira que percebe a si mesma e o mundo que a circunda. ${ }^{21}$ Os outros significantes promovem com as crianças interações e formas de convivência social. No contexto da institucionalização, são os cuidadores que passam a representar estes outros significantes, representando os modelos para as crianças, com um papel central na vida delas. ${ }^{5}$ Contudo, a interação protetora só ocorrerá quando os envolvidos estiverem vigilantes e comprometidos uns com os outros.

\section{Considerações finais}

Com base nos resultados, pode-se compreender o papel da interação social, atendendo ao objetivo do estudo. Assim, identificou-se que cuidadoras e crianças passam, constantemente, por 
Perspectivas adotadas pelos cuidadores na interação com a criança institucionalizada | 14

mudanças, criando e recriando sua forma de ver e agir no mundo. As cuidadoras, por meio da interação, adotam e modificam ideias, atitudes e valores, passando a ressignificar sua própria vida, valorizando mais sua família, tendo mais amor, compreensão e empatia com os outros, bem como percebendo que a criança muda suas concepções na interação com elas.

Nesse sentido, as cuidadoras agem de acordo com sua definição que surge da interação social que têm com as crianças institucionalizadas e do pensamento acerca de seus valores de vida, sendo que a situação presente das cuidadoras, vivenciando o cuidado da criança institucionalizada, faz diferença sobre suas formas de agir no mundo. Na relação com as crianças, as cuidadoras interagem, pensam, definem, aplicam seu passado e tomam decisões em seu presente embasadas nos fatores da situação imediata, passando a adotar novas formas de agir e interagir com os outros.

Acredita-se que os resultados deste estudo forneçam informações sobre a percepção do cuidador, ressaltando como implicações para prática a necessidade de oferecer a ele um espaço deescuta para que possa (re)pensar suas práticas de cuidado e como elas influenciam e são influenciadas pelo seu cotidiano. Nesse contexto, o enfermeiro pode desempenhar um papel importante, inserindo-se nos ambientes de acolhimento infantil e proporcionando um suporte aos profissionais cuidadores que ali atuam.

As limitações do estudo estão relacionadas ao fato de se considerar uma realidade específica, no entanto, por se tratar de uma pesquisa qualitativa, não aspira generalizações. Acredita-se que o presente estudo possa instigar o desenvolvimento de novas pesquisas que busquem saber como a prática do cuidado, na institucionalização infantil, age sobre as concepções do cuidador em outros contextos de acolhimento, tais como casas-lares e famílias acolhedoras, a fim de auxiliar na identificação de fragilidades e potencialidades, favorecendo assim a elaboração de estratégias de melhoria da qualidade do cuidado prestado. 


\section{Referências}

1. Charon J. Os símbolos, o eu e a mente: nossa natureza ativa. In: Charon J, Vigilant LG. Sociologia. 2a ed. São Paulo: Saraiva; 2013. p. 208-23.

2. Medeiros BCD, Martins JB. O estabelecimento de vínculos entre cuidadores e crianças no contexto das instituições de acolhimento: um estudo teórico. Psic Ciênc Prof [Internet]. 2018 [acesso em 2018 nov 27];38(1):74-87. Disponível em: http://www.scielo.br/pdf/pcp/v38n1/1414-9893-pcp-38-010074.pdfdoi:10.1590/1982-3703002882017

3. Rocha PJ, Arpini DM, Savegnago SDO. Acolhimento institucional: percepções de familiares que o vivenciaram. Arq Bras Psicol (Rio J 2003) [Internet]. 2015 [acesso em 2017 dez 13];67(1):99-114. Disponível em: http://pepsic.bvsalud.org/pdf/arbp/v67n1/08.pdf

4. Charon JM. Symbolic Interactionism: an introduction, an interpretation, an integration. $10^{\text {th }}$ ed. Boston: Pearson Prentice Hall; 2010.

5. Hueb MFD. Acolhimento institucional e adoção: uma interlocução necessária. Rev SPAGESP. 2016; 17(1):28-38.

6. Charmaz, K. A construção da teoria fundamentada: guia prático para análise qualitativa. Porto Alegre: Artmed; 2009.

7. Santos JLG, Erdmann AL, Sousa FGM, Lanzoni GMM, Leite ALSF. Perspectivas metodológicas para o uso da teoria fundamentada nos dados na pesquisa em enfermagem e saúde. Esc Anna Nery Rev Enferm [Internet]. 2016 [acesso em 2017 mar 10];20(3):e20160056. Disponível em:

http://www.scielo.br/pdf/ean/v20n3/1414-8145-ean-20-03-20160056.pdfdoi: 10.5935/1414-8145.20160056

8. Brasil. Ministério da Saúde. Conselho Nacional de Saúde. Resolução n. 466, de 12 de dezembro de 2012: diretrizes e normas regulamentadoras de pesquisa envolvendo seres humanos [Internet]. 2012 [acesso em 2017 mar 10]. Disponível em: http://www.conselho.saude.gov.br/resolucoes/2012/Reso466.pdf

9. Medeiros EGMS, Leite RFB, Ramos DKR, Almeida LAL. Repercussões do câncer infantil no cotidiano do familiar cuidador. Rev RENE [Internet]. 2014 [acesso em 2017 ago 02];15(2):233-9. Disponível em: http://www.periodicos.ufc.br/rene/article/view/3128/2402 doi: 10.15253/2175-6783.2014000200007

10. Oliveira PR, Schirmbeck TME, Lunardi RR. Experiences of a nursing team with death of a hospitalized indigenous child. Texto \&Contexto Enferm [Internet]. 2013 [acesso em 2018 nov 27]; 22(4):1072-80. Disponível em: http://www.scielo.br/pdf/tce/v22n4/en_25.pdf doi: 10.1590/S010407072013000400025

11. Fresia Solís F. Valores humanos y sociales que sostienen el trabajo del cuidador/a de niños en condición de discapacidad severa: un estudio cualitativo, exploratorio. Rehabil Integral 2013;8(2):54-63. 
12. Benedetti GMS, Higarashi IH, Sales CA. Experiences of mothers an fathers of children and adolescents with cancer: a phenomenological-existential heideggerian approach. Texto \&Contexto Enferm [Internet]. 2015 abr-jun [acesso em 2017 mar 10];24(2):554-62. Disponível em: http://www.scielo.br/pdf/tce/v24n2/0104-0707-tce-24-02-00554.pdfdoi: 10.1590/0104-07072015002702014

13. Lindolpho MC, Oliveira JB, Sá SPC, Brum AK, Valente GSC, Cruz TJP. The impact of nurses' performance in the view of the caregivers of elderly with dementia. Rev Pesqui Cuid Fundam [Internet]. 2013 [acesso em 2017 mar 10];6(3):1078-89. Disponível em: http://www.seer.unirio.br/index.php/cuidadofundamental/article/view/3452/pdf_1360doi:10.9789/2175$5361.2014 \mathrm{v} 6 \mathrm{n} 3 \mathrm{p} 1078$

14. Brazão JCC. A implicação do afeto na psicologia do desenvolvimento: uma perspectiva contemporânea. Psicol Ciênc Prof[Internet]. 2015 [acesso em 2017 ago 02];35(2):342-58. Disponível em: http://www.scielo.br/pdf/pcp/v35n2/1982-3703-pcp-35-2-0342.pdf doi:10.1590/1982.370302222013

15. Baltor MRR, Borges AA, Dupas G. Interação com a criança com paralisia cerebral: comunicação e estigma. Esc Anna Nery Rev Enferm [Internet]. 2014 [acesso em 2017 ago 02];18(1):47-53. Disponível em: http://www.scielo.br/pdf/ean/v18n1/1414-8145-ean-18-01-0047.pdfdoi: 10.5935/1414-8145.20140007

16. Alvarenga P, Malhado SCB, Lins TCS. O impacto da responsividade materna aos oito meses da criança sobre as práticas de socialização maternas aos 18 meses. Estud Psicol (Natal) [Internet]. 2014 [acesso em 2017 ago 02];19(4):305-14. Disponível em: http://www.scielo.br/pdf/epsic/v19n4/a08v19n4.pdf doi: 10.1590/S1413-294X2014000400008

17. Lemos SCA, Gechele HHL, Andrade JV. Os vínculos afetivos no contexto de acolhimento institucional:Um estudo de campo. Psicol Teor Pesqui [Internet]. 2017 [acesso em 2018 fev 11];33:1-10. Disponível em: http://www.scielo.br/pdf/ptp/v33/1806-3446-ptp-33-e3334.pdfdoi: 10.1590/0102.3772e3334

18. Pereira ARPF, Matsue RY, Vieira LJES, Pereira RVS. Análise do cuidado a partir das experiências das mães de crianças com paralisia cerebral. Saúde Soc [Internet]. 2014 [acesso em 2017 ago 02];23(2):616-25. Disponível em: https://www.revistas.usp.br/sausoc/article/view/84894/87630doi: 10.1590/SO10412902014000200021

19. Alcioli RML, Barreira AK, Lima MLC, Lima MLLT, Assis SG. Evaluation of institutional foster care services for children and adolescents in Recife. Ciênc Saúde Colet [Internet]. 2018 [acesso em 2018 nov 28];23(2):529-42. Disponível em: https://scielosp.org/pdf/csc/2018.v23n2/529-542/en doi: 10.1590/141381232018232.01172016

20. Tryphonopoulos P, Letourneau N, Ditommaso E. Attachment and caregiver-infant interaction: a review of observational-assessment tools. Infant Ment Health J[Internet]. 2014 [acesso em 2018 jan 05];35(6):642-56. Disponível em: http://onlinelibrary.wiley.com/doi/10.1002/imhj.21461/pdf doi: 10.1002/imhj.21461 
21. Salinas-Quiroz F, Posada G. MBQS: método de evaluación para intervenciones en apego dirigidas a primera infancia. Rev Latinoam Cienc Soc Niñez Juv [Internet]. 2015 jul [acesso em 2017 mar 10]; 13(2):1051-63. Disponível em: http://www.scielo.org.co/pdf/rlcs/v13n2/v13n2a36.pdfdoi: $10.11600 / 1692715 x .13235280514$

\section{Autor correspondente}

Ruth Irmgard Bärtschi Gabatz

E-mail: r.gabatz@yahoo.com.br

Endereço: Av. Gomes Carneiro, no1, Faculdade de Enfermagem, Porto, Pelotas, RS

CEP: $96010-610$

\section{Contribuições de Autoria}

1 - Ruth Irmgard Bärtschi Gabatz

Contribuições: concepção e planejamento do projeto, obtenção de dados ou análise e interpretação dos dados; elaboração do rascunho ou na revisão crítica do conteúdo; aprovação da versão final do manuscrito.

2 - Eda Schwartz

Contribuições: concepção e planejamento do projeto, análise e interpretação dos dados; revisão crítica do conteúdo; aprovação da versão final do manuscrito.

3 - Viviane Marten Milbrath

Contribuições: concepção e planejamento do projeto, análise e interpretação dos dados; revisão crítica do conteúdo; aprovação da versão final do manuscrito.

\section{Como citar este artigo}

Gabatz RIB, Schwartz E, Milbrath VM. Perspectivas adotadas pelos cuidadores na interação com a criança institucionalizada. Rev. Enferm. UFSM. 2019 [Acesso em: 2019 jun 15];vol 9 ex:1-17. DOI:https://doi.org/10.5902/2179769228411 